\title{
Underwater noise of small personal watercraft (jet skis)
}

\author{
Christine Erbe ${ }^{\text {a) }}$ \\ Centre for Marine Science and Technology, Curtin University, GPO Box U1987, Perth, \\ Western Australia 6845, Australia \\ C.Erbe@curtin.edu.au
}

\begin{abstract}
Personal watercraft (water scooters, jet skis) were recorded under water in Bramble Bay, Queensland, Australia. Underwater noise emissions consisted of broadband energy between $100 \mathrm{~Hz}$ and $10 \mathrm{kHz}$ due to the vibrating bubble cloud generated by the jet stream, overlain with frequency-modulated tonals corresponding to impeller blade rates and harmonics. Broadband monopole source levels were 149, 137, and $122 \mathrm{~dB}$ re $1 \mu \mathrm{Pa} @ 1 \mathrm{~m}$ (5th, 50th, and 95th percentiles). Even though these are lower than those of small propeller-driven boats, it is not necessarily the broadband source level that correlates with the bioacoustic impact on marine fauna.

(C) 2013 Acoustical Society of America

PACS numbers: $43.30 . \mathrm{Nb}$ [GD]

Date Received: January 15, 2013 Date Accepted: February 26, 2013
\end{abstract}

\section{Introduction}

A small personal watercraft (PWC) is a recreational water mobile, also called water scooter (Fig. 1), or commonly referred to by brand names such as Jet Ski (Kawasaki), Wave Runner (Yamaha), or Sea-Doo (Sea-Doo). PWCs are typically less than $4 \mathrm{~m}$ in length, and carry the driver and one or two passengers sitting behind the driver. PWCs are powered by an inboard gasoline engine that drives a jet water pump. Water is taken in through the bottom of the PWC, drawn through an internal pipe housing an impeller, and expelled at a high pressure as a jet stream out the back of the PWC.

In-air noise is often cited as the number-one complaint about PWCs by beachgoers, waterfront property owners, and traditional boaters. Guidelines and regulations exist in several coastal zones. ${ }^{1}$ While PWCs - in terms of aerial broadband sound pressure level - are no louder than other personal motorboats, the "high-pitched whine," the "repetitive smacking of PWC hulls against the water and the tendency of PWC operators to circle about the same location for extended periods of time" exacerbate the noise. ${ }^{2}$

Hardly anything is known about underwater noise of PWCs and bioacoustic impacts on marine life. This article presents recordings and calculated monopole source spectra of PWCs to be used in combination with sound propagation models for environmental impact studies.

\section{Methods}

Two autonomous underwater acoustic recorders (AURAL-M2, developed by MultiElectronique, owned by JASCO Applied Sciences) with High-Tech Inc. HTI 96 hydrophones (sensitivity $-164 \mathrm{~dB}$ re $1 \mathrm{~V} / \mu \mathrm{Pa}$ ) were deployed off Pelican Park in northern Bramble Bay, Queensland, Australia, about $300 \mathrm{~m}$ from shore, in $2.5 \mathrm{~m}$ of water, in December 2008. They were set $50 \mathrm{~m}$ apart on the muddy seafloor with metal stakes. Gains were set such that the system sensitivities were -148 and $-154 \mathrm{~dB}$ re $1 \mathrm{~V} / \mu \mathrm{Pa}$, respectively, calibrated with a G.R.A.S. piston phone. The bandwidth was $6 \mathrm{~Hz}$ to $16 \mathrm{kHz}$. Two surface

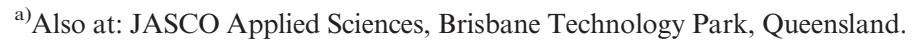




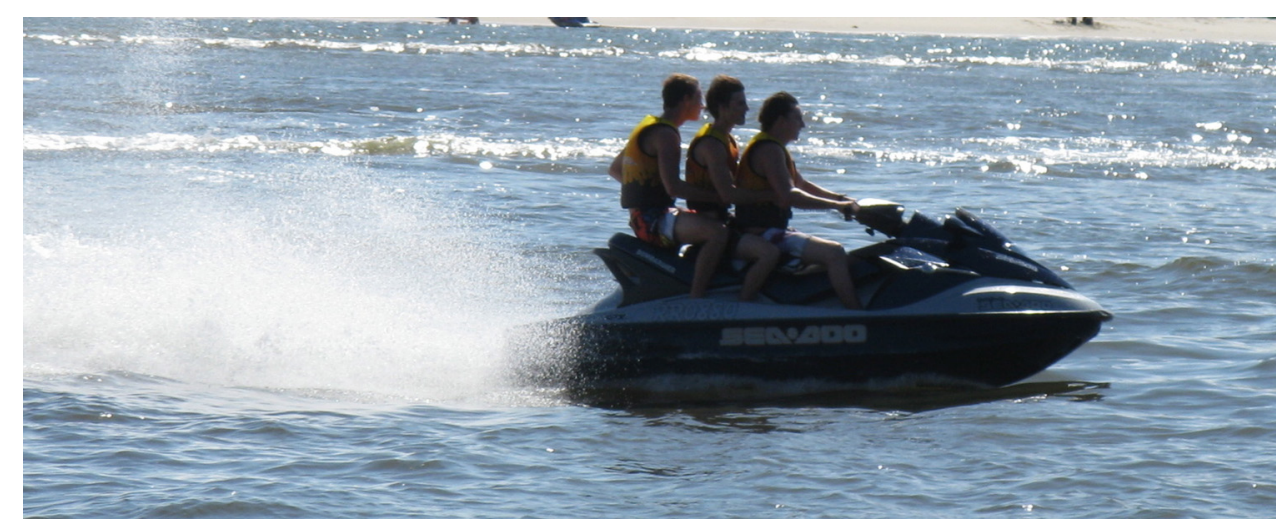

Fig. 1. (Color online) Photo of a PWC in Queensland.

floats marked their locations. The AURALs recorded continuously for $2 \mathrm{~h}$. Activities within $300 \mathrm{~m}$ from the AURALs were observed by two people with range-finding binoculars from the wharf and included PWCs, motorboats, and swimmers. One PWC drove eights around the two surface floats for $15 \mathrm{~min}$, clipping all data. A group of five teenage girls swam to one of the floats where they sang ABBA songs for $20 \mathrm{~min}$; unfortunately, this data (clearly recorded) also had to be discarded. A total of 66 PWC passes were recorded. It was impossible to identify all of the manufacturers and models. Some PWCs might have been recorded more than once, yet under different circumstances (different driver, speed, course, etc.). Most drivers changed speed and direction frequently. While the visual observers subjectively noted speed as "slow," "medium," or "fast" at the point of closest approach to either AURAL, all recordings were lumped for the computation of source spectrum percentile levels. No PWCs were recorded idling near the AURALs.

A $2 \mathrm{~h}$ spectrogram was computed for both datasets. The times of all events noted by the two visual observers were marked in the spectrograms and confirmed by listening to the corresponding sections. Samples of 4 to $20 \mathrm{~s}$ in length were extracted for each event, capturing the peak broadband energy. It was difficult to identify segments without PWCs, and a total of $4 \mathrm{~min}$ of ambient noise was extracted in bits and pieces in between PWC events. Power spectrum density levels were computed via fast Fourier transform. Sound transmission in Bramble Bay had previously been modeled using a Range-dependent Acoustic Model, ${ }^{3}$ and had been measured in the field, ${ }^{4}$ showing very little transmission loss below $1 \mathrm{kHz}$ over a $500 \mathrm{~m}$ range despite the shallow water. The same model was applied to compute PWC source spectra from received spectra, assuming a monopole depth of $1 \mathrm{~m}$ below the sea surface.

\section{Results}

PWCs were clearly audible above ambient noise over the longest ranges observed visually $(300 \mathrm{~m})$. A 5 -min spectrogram of 5 PWC passes is shown in Fig. 2. Each pass is identified as a broadband (vertical) "line" of energy. Wiggly lines between 100 and $800 \mathrm{~Hz}$ in the spectrogram are frequency-modulated tonals corresponding to impeller blade rates and harmonics. A scatter plot of all recorded received spectra at one site is shown in Fig. 3 (left panel). Ambient noise spectra recorded at the same site are overlain in black. There was a $15 \mathrm{~Hz}$ hump in nearly all PWC spectra, more pronounced at close range; this is also obvious in Fig. 2. Apart from this hump, all PWC spectra surpassed ambient noise only between $100 \mathrm{~Hz}$ and $10 \mathrm{kHz}$. This bandwidth was chosen for the computation of source spectra. Figure 3 (right panel) shows the percentiles of the source spectra of all PWCs at both sites. The $n$th percentile gives the level that is exceeded $n \%$ of the time. The 50th percentile is the median. The lower dark curves 


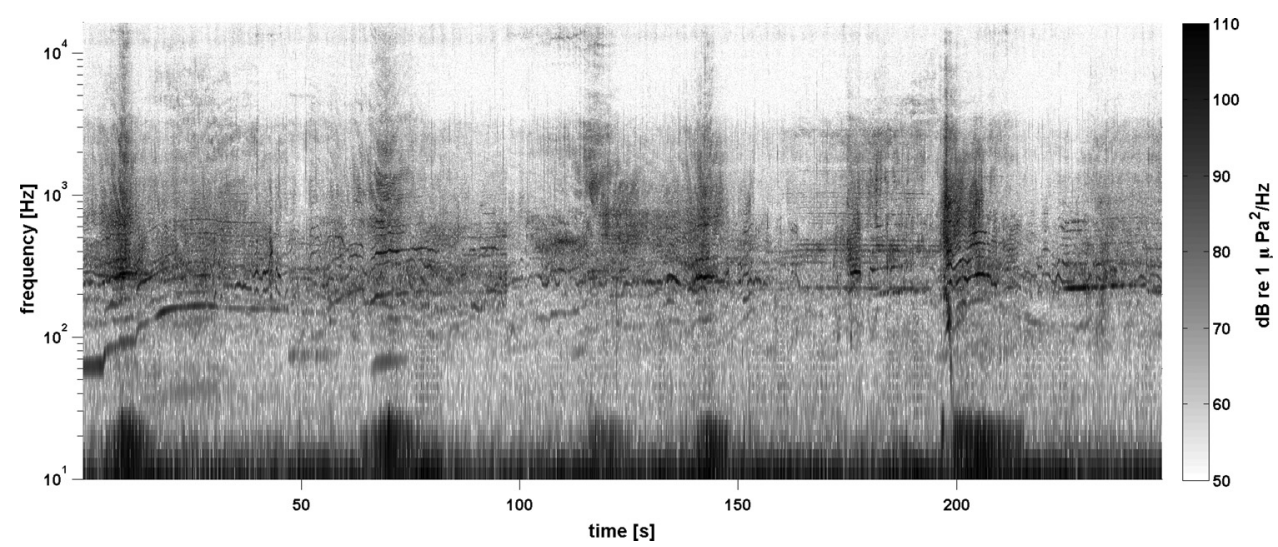

Fig. 2. Spectrogram of five PWC passes. Note the energy at $15 \mathrm{~Hz}$ with each pass. Impeller tonals are visible as frequency-modulated "black lines."

show the median ambient spectra at both sites. The black curve corresponds to the site closer to the wharf and shows the characteristic peak ( 2 to $10 \mathrm{kHz}$ ) of snapping shrimp in tropical water. ${ }^{5,6}$ There was hardly any snapping shrimp noise at the other site. One-third octave band levels of PWC noise are listed in Table 1. The broadband $(100 \mathrm{~Hz}$ to $10 \mathrm{kHz})$ monopole source levels were 149,137 , and $122 \mathrm{~dB}$ re $1 \mu \mathrm{Pa} @ 1 \mathrm{~m}$ (5th, 50th, and 95th percentiles).

\section{Discussion}

Underwater noise from PWCs was broadband, overlain with harmonically-related tonals mostly between $100 \mathrm{~Hz}$ and $1 \mathrm{kHz}$. PWC impellers typically run at $>4000 \mathrm{rpm}$ (less at lower speed) and have 3 to 4 blades, resulting in a blade rate frequency (rpm times the number of blades) $>100 \mathrm{~Hz}$. Blade rate tones and harmonics, which typically dominate the source spectra of propeller-driven boats, are usually expected weaker in jet-driven boats due to the internal placement of the propeller and due to the expulsion of the water jet, which creates a bubble cloud behind the vehicle that shields the propeller or engine noise. The oscillating bubbles (of variable size) themselves generate a
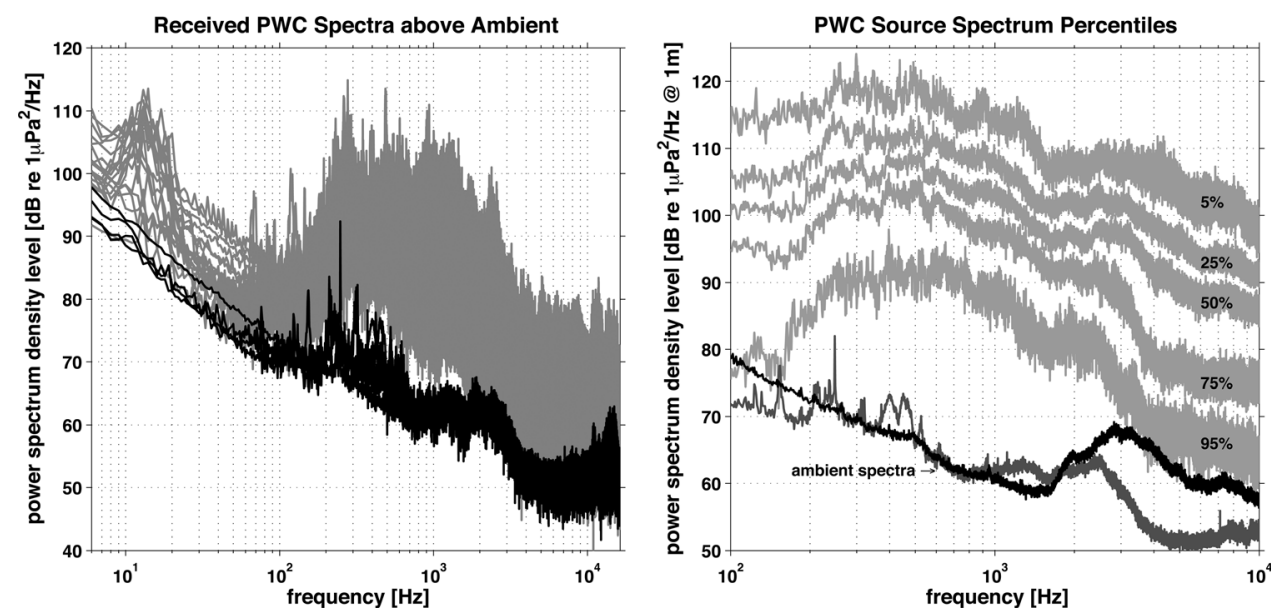

Fig. 3. (Left) Received spectra of PWC (gray) and ambient noise (black) at one of the sites. (Right) Computed monopole source spectrum percentiles (gray) and ambient noise (dark gray and black) at both sites. 
Table 1. One-third octave source levels SL [dB re $1 \mu \mathrm{Pa} @ 1 \mathrm{~m}$ ]: 5th, 50th, and 95th percentiles; fc: band center frequency.

\begin{tabular}{lccc}
\hline \hline $\mathrm{fc}[\mathrm{Hz}]$ & $\mathrm{SL}_{5}[\mathrm{~dB}]$ & $\mathrm{SL}_{50}[\mathrm{~dB}]$ & $\mathrm{SL}_{95}[\mathrm{~dB}]$ \\
\hline 100 & 128 & 115 & 92 \\
125 & 129 & 116 & 94 \\
160 & 131 & 116 & 97 \\
200 & 132 & 120 & 103 \\
250 & 136 & 124 & 108 \\
315 & 138 & 125 & 109 \\
400 & 138 & 127 & 112 \\
500 & 140 & 128 & 112 \\
630 & 138 & 127 & 114 \\
800 & 138 & 126 & 113 \\
1000 & 138 & 127 & 112 \\
1250 & 138 & 125 & 110 \\
1600 & 134 & 123 & 107 \\
2000 & 134 & 123 & 109 \\
2500 & 136 & 125 & 108 \\
3150 & 136 & 125 & 103 \\
4000 & 136 & 122 & 99 \\
5000 & 135 & 120 & 99 \\
6300 & 134 & 119 & 98 \\
8000 & 134 & 120 & 98 \\
10000 & 132 & 120 & 98 \\
\hline \hline
\end{tabular}

broadband spectrum. Tonal energy persisted over longer ranges than the noise from the vibrating bubble cloud.

While the mechanism for generating energy at $15 \mathrm{~Hz}$ at the times of PWC passes is unclear, low frequencies can propagate rather well even in this shallow water. ${ }^{4}$ The Queensland seafloor consists of a thin layer of unconsolidated sediment (sand to mud) on top of limestone bedrock, which has a shear speed similar to the compressional speed in water, allowing low frequencies (depending on grazing angle) to travel at very little loss. ${ }^{7}$

Monopole source spectra of PWCs were low in level, compared to small powerboats with peak power spectrum density levels between 300 and $500 \mathrm{~Hz}$ of 135 (at $3100 \mathrm{rpm}$ ) and 150 (at $4800 \mathrm{rpm}) \mathrm{dB}$ re $1 \mu \mathrm{Pa}^{2} / \mathrm{Hz} @ 1 \mathrm{~m},{ }^{8}$ compared to small whale-watching boats with a power spectrum density level of $142 \mathrm{~dB}$ re $1 \mu \mathrm{Pa}^{2} / \mathrm{Hz}$ at $100 \mathrm{~Hz}$ decreasing to $123 \mathrm{~dB}$ re $1 \mu \mathrm{Pa}^{2} / \mathrm{Hz}$ at $10 \mathrm{kHz},{ }^{9}$ and compared to high-speed race boats with broadband received levels of $128 \mathrm{~dB}$ re $1 \mu \mathrm{Pa} @ 300 \mathrm{~m} .{ }^{10}$

\section{Conclusion}

Even though PWCs are quieter underwater than boats, the sound pressure level might not be a good indicator of the bioacoustic impact. It is interesting to follow the debate of in-air noise of PWCs. According to the National Pollution Clearinghouse, PWCs have unique operational characteristics (e.g., continually leaving and re-entering the water, persistent changes in speed hence noise level and pitch, repetitive smacking of PWC hulls against the water, tendency to circle in one spot for long times) that make their noise more annoying than that of other motorized vessels. ${ }^{2}$

\section{Acknowledgments}

Thank you to Andrew King for help with the field work. 


\section{References and links}

${ }^{1}$ S. Currey, Personal watercraft (PWC) management guide: A comprehensive reference handbook,

Massachusetts Office of Coastal Zone Management, Boston, MA (undated).

${ }^{2}$ C. Komanoff and H. Shaw, Drowning in Noise: Noise Costs of Jet Skis in America (Noise Pollution Clearinghouse, Montpelier, VT, 2000).

${ }^{3}$ M. D. Collins, R. J. Cederberg, D. B. King, and S. Chin-Bing, "Comparison of algorithms for solving parabolic wave equations,” J. Acoust. Soc. Am. 100(1), 178-182 (1996).

${ }^{4}$ C. Erbe, "Underwater noise from pile driving in Moreton Bay, Qld," Acoust. Aust. 37(3), 87-92 (2009).

${ }^{5}$ A. F. Everest, R. W. Young, and M. W. Johnson, "Acoustical characteristics of noise produced by snapping shrimp," J. Acoust. Soc. Am. 20(2), 137-142 (1948).

${ }^{6}$ M. L. Readhead, "Snapping shrimp noise near Gladstone, Queensland," J. Acoust. Soc. Am. 101(3), 1718-1722 (1997).

${ }^{7}$ A. J. Duncan and A. Gavrilov, "Acoustic propagation over limestone seabeds," Acoustics 2009, Annual Conference of the Australian Acoustical Society (Adelaide, South Australia, 2009).

${ }^{8}$ M. L. Barlett and G. R. Wilson, "Characteristics of small boat acoustic signatures," J. Acoust. Soc. Am. 112(5), 2221 (2002).

${ }^{9}$ C. Gervaise, Y. Simard, N. Roy, B. Kinda, and N. Menard, "Shipping noise in a whale habitat: Characteristics, sources, budget, and impact on belugas in Saguenay-St. Lawrence Marine Park hub," J. Acoust. Soc. Am. 132(1), 76-89 (2012).

${ }^{10}$ S. Amoser, L. E. Wysocki, and F. Ladich, "Noise emission during the first powerboat race in an Alpine lake and potential impact on fish communities," J. Acoust. Soc. Am. 116(6), 3789-3797 (2004). 